\title{
Boosting affordability, acceptability and attractiveness of deep energy renovations of residential buildings - a people-centred ethnographic approach
}

\author{
Gregor Cerinsek ${ }^{1,}$, Domen Bancic ${ }^{1}$, Dan Podjed ${ }^{2}$, Simona D’Oca ${ }^{3}$, Jure Vetrsek ${ }^{1}$, Slavko Dolinsek ${ }^{1}$ and Peter op't Veld ${ }^{3}$ \\ ${ }^{1}$ Institute for Innovation and Development of University of Ljubljana, Kongresni trg 12, 1000 Ljubljana, Slovenia \\ ${ }^{2}$ Reseach Centre of the Slovenian Academy of Sciences and Arts, Novi trg 2, 1000 Ljubljana, Slovenia \\ ${ }^{3}$ Huygen Installatie Advies, Parkweg 22B, 6212 XN Maastricht, Netherlands
}

\begin{abstract}
A prevailing perception within the research field of energy and buildings is that buildings - and not people - consume energy. Researchers and practitioners often neglect the important effect of the actual behaviour of people living or working in buildings, together with the values, habits, motivation factors, and other practices connected to the energy use. The key aim of this paper is to demonstrate the added value of the ethnographic approaches and interdisciplinary analysis for understanding and influencing human behaviour to support and enhance deep energy renovation of residential buildings. It presents the methodology together with preliminary findings from a demonstration study in Slovenia. It concludes by providing case-specific recommendations in terms of affordability, acceptability and attractiveness by considering everyday lifestyles, motivations, and issues faced by actors involved in the renovation processes.
\end{abstract}

\section{Introduction}

\subsection{Motivation}

As noted by several recent European policies in the field of energy efficiency [1] buildings are responsible for approximately $40 \%$ of energy consumption and $36 \%$ of $\mathrm{CO} 2$ emissions in the EU. In addition, almost $75 \%$ of the building stock is energy inefficient, while only $0.4-1.2 \%$ of the building stock is renovated each year. Logically, more renovation of existing buildings has the potential to lead to energy savings - potentially reducing the EU's total energy consumption. Improving the energy efficiency of buildings can also generate other economic, social and environmental benefits. Better performing buildings provide higher levels of comfort and wellbeing for their occupants, and improve health by reducing illnesses caused by a poor indoor climate. It also has a major impact on the affordability of housing and on the concept of energy poverty.

\subsection{Challenge}

The basic understanding that "buildings consume energy" (and not people who live or work in them) is still predominant in the energy efficiency discourse [2] and is to some extent also obvious from previous paragraph. The concept of technical potential has been a fundamental tool for the energy efficiency industry and is based on engineering and economic calculations which are performed "without concern for the probability of successful implementation" $[3,4]$. Technical potential scenario assumes that the energy efficiency technologies are appropriate for all building configurations, infinitely available or below the cost considered, and have no economic, social, psychological risks that would dissuade consumers or organizations from adopting them. Within this arena, humans enter implicitly as generating energy service needs and as economic agents who evaluate and purchase goods with respect to the cost-effectiveness of their future expected energy savings [5]. In this sense people are not seen as creators of improved energy use, but rather as disturbing factors or barriers to such improvements since they are not able to understand what is in their best interest. The results have been a set of top-down views of people and energy that are ill-equipped to recognize heterogeneity, social organization, or interests beyond energy and economic rationality [6].

\subsection{The TripleA-Reno Ethnographic Approach}

Solely technological solutions and economic and business arguments based on benefits are often insufficient to deliver the necessary change our society seeks for [1]. If the renovation rate in EU needs to increase from the present level of $1.2 \%$ per year to at least $2-3 \%$, we must simultaneously take into account both, the technological developments and changes in human behaviour. To understand how human behaviours

\footnotetext{
* Corresponding author: gregor.cerinsek@iri.uni-lj.si
} 
affect energy demand and uptake of new technologies the "energy studies need social sciences" [7]. The sociological, psychological and anthropological theories together with their research and analytical methods can provide measurable improvement in promoting energy conservation, which is affected by both behaviour and technology. As D'Oca [8] argues, the solution is not simply to include social science and humanities as an afterthought in a physical context, but rather as an "equal partner" [9]. In the broader perspective the priority must be given to interdisciplinary research on energy consumption, which conveys the knowledge, methods, and metrics of building physics, economic, policymaking, and social science and humanities research altogether [10].

With this picture in mind, the vision of the TripleAReno EU H2020 project is to promote widespread energy renovation of existing European housing stock and empower individuals and communities in favour of such developments. The first stage of the project aims to enhance understanding of different contexts and processes of energy renovation. To achieve this, several case studies are being implemented and studied in different EU member states. Since the focus of TripleAReno project is on the end-users (i.e. building occupants) and other stakeholders involved in the renovation activities, the qualitative ethnographic methods have been used to analyse and explain how specific contexts influence the processes in hand. The analysis and crosscomparison of results from different case studies will portray the complexity of renovation processes by considering everyday realities, motivations, and issues faced by all actors involved in the renovation processes.

The ethnographic inquiry is perceived as a "trademark" methodology of anthropology. The conventional and primary ethnographic method is the participant observation, where "the researcher takes part in the daily activities, rituals, interactions, and events of a group of people as one of the means of learning the explicit and tacit aspects of their life routines and their culture" [11]. Transferred to non-academic settings, ethnography proved to be highly valuable, but was often also perceived as time- and resource-consuming, or nongeneralizable due to its focus on individuals and small groups [12]. The so called "rapid ethnography" or "rapid observation" is a type of ethnographic research adapted to non-academic, corporate settings' time constraints. The method employs a number of research techniques, including qualitative interviews, focus groups, fieldwork (participant observation), video and sensory ethnography [13], and shadowing (following and observing individuals throughout a certain short period of time). Some of the key ethnographic research techniques in the "corporate encounter" are summarized below [14,15]:

- Using all five senses, the ethnographer serves as the primary tool of data collection, living or staying in a context for an extended period of time.

- Participating in a wide range of activities that are both routine and extraordinary, along with the people who are the full participants in that context.

- Recording observations and thoughts, usually chronologically, in fieldnotes in a variety of settings.
- Learning from and building on the perspectives of the people in the research setting inductively, using both explicit and tacit information in analysis and writing, to develop local theories for testing and then adapting these theories for general use.

The study approach described in next chapters is based on the 4-step people-centred development framework (see Figure 1) developed in the PEOPLE project (www.people-project.net). The concept of the people-centred development is based on the following key premises:

- People should be involved in all development phases in order to create meaningful, relevant, useful, socially responsible, user-friendly, and sustainable solutions by generating new concepts and ideas, shaping products, forming services, testing prototypes or existing products and services. People are thus considered more than just "users". Instead, they become active co-creators of solutions.

- The dialogue between engineers, developers, research, design teams, and people (potential users of new solutions) should be ongoing throughout the development process, including design. Research should be part of the creative process in product and service development, and not merely a problem-solving tool.

- Researchers with backgrounds in anthropology, sociology or psychology have the unique knowledge, methods, and skills for creating a link between industry and people, thus enabling and supporting the transition from users to active co-creators.

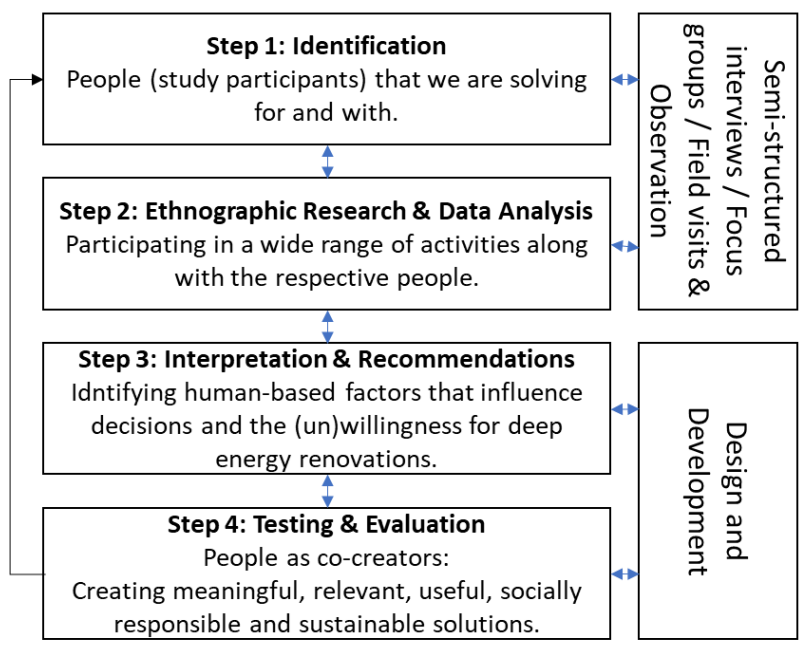

Fig. 1. 4-step people-centred development framework

The paper aims to contribute to the existing fields of knowledge and methodological practices in the energy efficiency area by demonstrating how ethnographic approaches and interdisciplinary research and analysis can enhance understanding of human behaviour in order to support deep energy renovation of residential buildings. New research has been recently developed that presents this integrated methodology together with preliminary findings from a demonstration study in Slovenia. It concludes by providing case-specific recommendations in terms of affordability, acceptability and attractiveness by considering everyday lifestyles, 
motivations, and issues faced by actors involved in the renovation processes.

\section{Method}

\subsection{Case Description}

The case study is located in a medium-sized town (approx. 7,000 inhabitants) in the central part of the Republic of Slovenia. The focal point of our study is a block of flats located in the heart of the town, built in 1976. Its outside appearance - reddish brick façade and concrete accented elements - gives a distinct impression of the era in which it was constructed. The design combines spaces of mixed designation: residential space in top floors and business premises in the ground floors. Today the building contains 51 flats (ranging from 23 to $72 \mathrm{~m} 2$ in size), 4 business premises open to general public (two bars, a bank and a shop) and two other business spaces - a private gym and storage space.

\subsection{Study Participants}

Table 1 presents the participants' profiles of the TripleAreno ethnographic study.

Table 1. Study Participants.

\begin{tabular}{|c|c|}
\hline Participants & Description \\
\hline $\begin{array}{l}\text { Building } \\
\text { occupants }\end{array}$ & $\begin{array}{l}\text { Individuals who de facto live or use the } \\
\text { building that is planned for renovation. The } \\
\text { occupants of the case study building are in } \\
\text { the centre of our study. Firstly, we are } \\
\text { interested in their everyday interaction with } \\
\text { the specific building. Secondly, we are } \\
\text { interested in how they - as a community of } \\
\text { building occupants - take part of and } \\
\text { influence the processes of deep energy } \\
\text { refurbishment. }\end{array}$ \\
\hline $\begin{array}{l}\text { Managerial } \\
\text { staff }\end{array}$ & $\begin{array}{l}\text { Individuals who are operatively involved in } \\
\text { management of renovation projects, } \\
\text { preferably on behalf of an institution } \\
\text { managing the renovation (e.g. representative } \\
\text { of a housing corporation). }\end{array}$ \\
\hline $\begin{array}{l}\text { Technical } \\
\text { staff }\end{array}$ & $\begin{array}{l}\text { Contractors or business representatives with } \\
\text { real life practical experience with } \\
\text { renovation projects both throughout the } \\
\text { preparations (project planning and business } \\
\text { negotiations) and project realisation (on site } \\
\text { and administratively). }\end{array}$ \\
\hline Others & $\begin{array}{l}\text { External observers (e.g. neighbours) or } \\
\text { people from the same area who live in } \\
\text { similar conditions, have experiences and } \\
\text { have already gone through a process of } \\
\text { renovation. }\end{array}$ \\
\hline
\end{tabular}

\subsection{Framework of Research Topics}

When conducting ethnographic study, the researchers observe the situation holistically and try to avoid focusing their analytical lenses exclusively on particular elements. To the same extent, they have to be careful not to be carried into extremes of over-generalising the scope of interest and over-discussing particular topics with limited relevance. Therefore, a framework of relevant themes and topics was set serving as a guidance tool before going on the field. It covers a broad spectrum of information that should be discussed and assessed during the study. The first section represents a set of general contextual topics related to the location, building, renovation project and other relevant social, economic, geographical, historic and demographic factors. In addition to field research, the data is gathered from existing building documentation, literature and other reliable sources. The second section focuses on the individuals (occupants and external) and institutions involved in the renovation project. These can either promote or impede the project depending on their interests, actions, and level of involvement. In addition, the research focus is also on daily energy use practices and indoor environment qualities - thermal comfort, sound, air quality, and light. Finally, the TripleA-Reno key aspects - affordability, acceptability and attractiveness of the renovation process - are highlighted and discussed.

\subsection{Study Implementation}

TripleA-Reno ethnographic study implemented the following qualitative research methods:

(1) Semi-structured interviews on specific topics related to deep refurbishment, energy use and indoor environmental quality were carried out. The framework of topics steered the conversation into the wanted direction. In contrary to structured interviews, the questions with clear cut answers and fast changes of the (sub)topics in discussion were generally avoided. Within the respective case study, we carried out 10 semistructured interviews, each lasting approximately 2 hours. 6 of them involved the building occupants, i.e. 5 individual apartment owners and 1 owner of business premises. In addition, 2 of them were carried out with key external stakeholders involved in the renovation processes, i.e. the building designer (representing technical stuff) and the director of the Housing Corporation (representing managerial stuff). The last 2 interviews involved external experts having experiences with similar past cases, i.e. the director of a construction company and a neighbour who lives in a recently renovated block of flats and oversaw the whole process. With informants' consent, the researcher recorded the conversations.

(2) Focus group discussions were carried out in interactive group settings to identify perceptions, opinions, beliefs, and attitudes towards deep refurbishment and energy use of people living in the building. The researchers facilitated the discussion and studies the verbal and non-verbal reactions of participants. During the discussion process, the researchers took notes and recorded the vital points they were getting from the group. The focus group was demonstrated as a useful tool to gather large quantity of 
useful information and was especially relevant when involving individuals, who would otherwise decline an interview or claim they do not have anything relevant to say about the discussed topic. 4 different focus groups were carried out involving small (3-5), but rather diverse group of occupants.

(3) Field visits incorporated different qualitative research methods, such as participant observation, home and building tours together with sensory ethnography [16]. Key aim was to gain a close and intimate familiarity with people and their energy use practices through an intensive involvement in their home environment. Timewise, this was carried out after the semi-structured interviews and lasted app. 2 hours each. During the observation, the researchers gathered visual materials (photos or videos using smart phones and video cameras) capturing everyday lifestyle stories and activities of occupants (see Figure 2 as an example). Ethnographic fieldwork diary was used to record the fieldnotes.

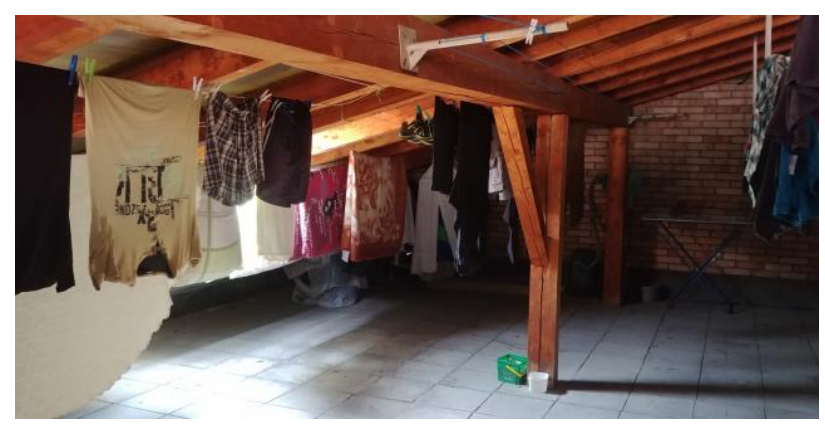

Fig. 2. Improvised slanted roofing on top of the building (from sensory ethnographic research)

\subsection{Data Analysis}

The interview and focus group transcripts together with audio and video recordings and field notes from the observation were examined taking into account the study objective, i.e. discovering what are the different humanbased factors (e.g. habits, motivation, values, assumptions etc.) that influence decisions and the (un)willingness for deep energy renovations of residential buildings in the specific research case. Mainly based on the deductive approach, the predefined framework of topics together with specific questions were used as a guide and structure for grouping and analysing the collected data. Next, the inductive reasoning was used when specific new observations and insights emerged from collected data to form more general principles which were not covered initially within the framework. Descriptive and pattern data coding was used to categorize data into concepts and patterns in order to gain deeper insight into the meaning of the data. Finally, the research findings have been elaborated based on the study objectives and with a reference to project's three pillars - affordability, acceptability and attractiveness of renovation.

\section{Results}

The respective section presents summary of key research results deriving from ethnographic study and analysis of collected qualitative data. Firstly, some general contextual insights are presented (Subchapter 3.1). Next, we demonstrate the results that relate to attractiveness (Subchapter 3.2), acceptability (Subchapter 3.3) and affordability (Subchapter 3.4) of deep renovation in the specific case.

\subsection{Context}

The town has been described as attractive, green and lively with a relatively high quality of living. It offers the benefits of living in a town, such as frequent sociocultural events and a variety of services, while retaining the feeling of being close to the nature at all times. The street on which the case study building is located used to be the main road leading through the town until the construction of a bypass road around. The change significantly improved the quality of life for the building occupants by reducing noise and making the immediate surrounding of the block safer and more liveable.

Ethnography results report several technical deficiencies of the building. Besides poor insulation people most frequently mentioned insufficient water drainage and poorly solidified foot of the hill on the north corner of the block. Cracks combined with poor drainage most dramatically affect the cellars, which are constantly damp and dripping with water in rainy conditions. People also report on the poor ventilation system in the bathrooms, which results in occasional bad smell coming from the ventilation shafts into the flats. Finally, we have to mention the poor flat-roof design. Top floors had serious problems with dampness and leakage until improvised slanted roofing was put in place (see Figure 2).

All of the above suggests that the design of the building was not well thought-out and that its construction was poorly managed and monitored. Results demonstrate that the building was designed short-sightedly, focused on workers' families and not accounting for the future - the ageing of generations, the old and disabled, and changing lifestyles. As for the poor construction qualities, some people claim it is a consequence of rushed construction processes. Supposedly, the contractors were trying to avoid delays by possible archaeological excavations. To save time, they did a superficial job in solidification and drainage of the foothill terrain north of the building.

Most of the households within the building own their flats. Most of them also have a steady income (salary or pension) that allows for a decent life. A significant proportion of the owners have been living in the block since before Slovenia gained independence from Yugoslavia in 1991. These nowadays middle and third age generations were originally tenants, which were granted flats through a public housing model supported by the socialist government at the time. In recent years, 
with the passing of generations, young families and individuals have started to move in.

\subsection{Affordability of Renovation}

Affordability seems to be considered as one of the key aspects related with renovation projects. From our fieldwork experience, we can support such conceptions to a certain extent. Here are some of our key findings.

-Affordability does not always prove to be a factor of attractiveness of renovation projects. It is rather a function of acceptability. In other words, if people do not find the renovation affordable, they will not find it acceptable.

-The notion of affordability does not necessarily translate into financial terms. People often tend to prioritise the prospective results, such as visual (aesthetic) appearance of the building, the better indoor environmental quality (IEQ) and comfort of the flat, and the feeling that they have participated in a project that is in the interest of the wider community.

-While younger generations tend to see their financial participation in the project as an investment into their assets, the older generations often tend to see it as an investment for the younger generations of their family.

-Speculations about long-term savings coming from the renovation can be misleading. Individuals interested in the renovation should also be presented with possible risks, such as dangers of bad quality work done by the contractor.

\section{3 (Un)attractiveness of Renovation}

One of the key aims of our study is to analyse what makes renovation projects attractive for individual owners and other key stakeholders. Here are some key findings on why they find it attractive:

-Financial reasons. People find investments into renovation project attractive for prospects of long-term savings. In addition, they see it as an investment that increases the financial value of their property. It is also a higher chance of engagement and support from the side of the building occupants if the costs of living are considered disproportionally high in comparison with similar buildings.

-Aesthetic reason. Individuals sometimes find outer appearance of their building more important than any other reason. This could also be interpreted as a function of public appearance and conformation with the social standards.

-Personal reasons (values and principles). Some individuals state environmental values and principles as their primary reason for supporting the renovation. For majority, however, this is a secondary motivation, coming after financial, aesthetic and prospects of IEQ. Sometimes a sense of comradery is also apparent. Those individuals, who have less reasons to support the renovation because they are content with their current situation find their reason in solidarity with other occupants who depend on their support to realize the renovation.
-Prospects of better IEQ. One of the general primary considerations for support of renovation is improved aspects of IEQ - thermal comfort, sound, air quality and light. This is especially true with individuals that face serious issues with IEQ in their flats.

-Prospects of improved qualities of the building. Some find the idea of energy renovation attractive because it is a good chance for other types of changes which would overall improve the functioning and qualities of the building and surroundings.

The above findings also have its flip side. Here are some considerations that render renovation unattractive:

-Financial reasons. For some, the initial costs of renovation outweigh the prospects of future savings. Specific reasons are poor household financial incomes, possibilities for inefficient realisation of the project, and seemingly overly expensive materials or solutions.

-Aesthetic reasons. Since aesthetics is largely a subjective category some individuals deny support of the renovation exactly because they feel the new appearance of the building will be worse than the old one.

-Personal reasons. It is not uncommon that some individuals decline their support of a project because of a certain resentment they have against a person who promotes the renovation. This can be non-related with any objective and rational arguments for or against the renovation.

-Prospects of technical complications. Some individuals distrust either the contractor or the materials used for renovation. This can be a strong enough factor for individuals to deny their support for the project.

-The disruption of everyday life. One of the major reasons that renders such projects unattractive is the disruption of everyday life. It forces people to make adjustments to their everyday routines, sometimes for extended periods of time. It also involves unwanted yet inevitable noise and dirt.

-Time consuming. Similar to the above, such projects require individuals to invest efforts and time into realising it.

\subsection{Acceptability of Renovation}

Acceptability is the tipping point of decision-making. If a solution or a project fails to be acceptable for all parties involved, it is likely to face issues in one or more segments of its realisation. Here are some key findings on acceptability regarding energy renovation projects:

-People are more likely to support the project if they are convinced that their investments will have positive returns in at least one of the two key aspects - financial savings or improved quality of life. The later, among others, includes improved IEQ, aesthetic aspects and social acceptance.

-It is more likely that people will find renovation projects acceptable if they are well educated about the key aspects of the project - technical, financial and practical. 
-It is more likely that people will find a project acceptable if it is managed by, in their opinion, a trustworthy person.

-Similarly, people would be more likely to support and get actively involved with the project if there would be some sort of a reliable guarantee that the renovation is not going to cross certain limitations - deadlines, budgets etc.

-People are more likely to support the renovation if the solutions are widely recognised and established as efficient.

-Individual owners are not likely to consider the renovation acceptable if they at the same time will not consider it affordable. At least in the case of a façade renovation, that largely depends on the ratio of the property's floor surface to its outer wall surface.

-People find renovation unacceptable if they feel someone involved in the project has illegitimate benefits from it. Cases of corruption and possible frauds are a major source of frustration especially for the housing community.

-Choosing the right contractor is of key importance. If people do not trust the contractor, the project is not likely to gain enough support. This partially requires also rigid supervision by trustworthy (uncompromised) building inspector.

\section{Discussion with Recommendations}

Our results demonstrate that the decision-making process in multi-apartment buildings are complex and it is challenging to reach consensus among all involved stakeholders. Each project has to be tailored to the needs of the specific building, occupants and the relevant contexts, taking into account specifics such as building and urban typology, household structures, personal and socio-economic situations, geography and climate zones, market, availability of technical solutions, comfort level and IEQ, culture, social practices and (local) politics. There is a need for a competent "community manager" or "project facilitator" that would oversee and manage the complex process of deep renovation; as well as facilitate and lead the communication between stakeholders involved. They should act as integrators understanding the market (e.g. available technologies, funding instruments, experts and certified building professionals etc.), community and broader environment. They should furthermore be able to critically examine complex information, make proper selection, translate and provide information in an understandable manner to the end users (i.e. during the design, installation and operational phases). Basic ethnographic research should be carried out to identify and map the stakeholders and their ability to influence outcomes (e.g. power to support or obstruct the renovation process).

Gaining peoples' trust is key for success of a renovation project. Renovations are acceptable if all parties involved are reassured that it will be worth their time, effort, and financial investment. Examples of similar successful projects with the real impact should be demonstrated, ideally coming from their community or close surroundings. These include testimonials, visual material (e.g. before and after) together with live and verified measurements from real cases (IEQ and energy reductions). For instance, the ambassadors of successful projects from other communities (e.g. early adopters and trendsetters) are able to demonstrate how concrete challenges can be solved and how difficult projects can be realized. In addition, there is a need to identify the so called "local heroes" who de facto live in the building and have already gained trust from other occupants. These representatives are able to mediate and solve conflicts within the housing community and can also facilitate the communication.

Any major work on the flat, be it renovation of an individual space within the unit or the unit as a whole, disturbs the everyday life of people (also noise and dirt during the construction phase). People may need to relocate and landlords might lose income from rent. It is therefore crucial that a detailed timeline is presented to them together with a strategy of minimizing the impact on the occupants' daily routine. The project should be clearly split into phases, so that people can easily observe the progress from phase to phase (and receive feedback). Potential disruptions and delays should be addressed in a suitable way (mitigation, communication to stakeholders). In terms of financial investments and gains, different scenarios, typified business plans and the projections of long-term higher value of real-estate should be presented to people in a simple and understandable way, such as answering on "How much does my building consume?", "How much will it consume after renovation?", "How much money would we save after the renovation and how long would it take?".

Finally, it is crucial to study and understand the broader context, as it represents one of the main determinants of energy behaviours and social change. People learn which behaviours are culturally and socially recognized in the context and the constant repetition creates the social practice. Changing a social practice requires a deepen process in which individuals and groups negotiate new actions with old ones through social learning. In particular, social practice change requires the understanding of the reasons behind the change (e.g. environmental footprint associated to the old practice) and the participation to a new practice through individual and collective experience and training. In this sense the community-based initiatives might move from cognitive to systemic change. The disturbance brought by the building retrofit could present an ideal momentum to foster new behavioural and social change. The change could happen on individual, family or on building level but also broader, neighbourhood level (e.g. lowering the rates of criminal activities due to renovation).

\section{Conclusion and Future Work}

The key and overarching position of respective paper is that studying human behaviour must play an important part in the broader field of energy research and that 
separate discipline lenses alone could not provide the complexity of knowledge needed for understanding and influencing human interactions with energy systems. TripleA-Reno ethnographic people-centred approach aims to enhance understanding of various aspects of human experience and social processes in their complex entirety and in "real-life" settings. It provides a tool for in-depth study of people and different human-based factors (e.g. habits, motivation, values, assumptions etc.) that influence decisions and the (un)willingness for deep energy renovations of residential buildings. In addition, the methodology aids to discover and describe the relations between building occupants and the building, as well as their relations and roles within the renovation processes. Summarizing the key results deriving from the ethnography study we can propose several recommendations to enhance deep energy renovation. Recommendations primarily relate to the specific study case; however, they could also be transferred to other similar contexts.

One of the key aims of the TripleA-Reno project is to provide to building occupants attractive and personalized information on energy use, indoor environment, health and lifestyle and to furthermore enhance deep energy renovations of existing European housing stock. In the frame of the future research work we will implement the described ethnographic methodology in 5 additional demo cases across Europe, which all differ in relation to building and urban type, household structure, geography and other context specifics. In addition, we will compare the qualitative results from ethnographic study with large-scale quantitative study involving broader sample of occupants from respective case studies. The objective is to analyse and translate the study results collected through inquiry and provide concrete recommendations, which will furthermore influence the co-creation of the TripleAReno solutions and gamification platform.

\section{Acknowledgment}

The research reported in this paper is part of the "TripleAReno" project that has received funding from the European Union's Horizon 2020 research and innovation programme under grant agreement No 784972. In addition, several methodological principles implemented in respective study derive from the "PEOPLE" project that has received funding from the European Union's Erasmus+ Knowledge Alliance programme under grant agreement No. 2016-2870/001-001. We the authors of this paper assert our rights as authors and assert that the statements we make in the paper are true to the best of our knowledge and belief.

\section{References}

1. EU. High Energy Performing Buildings: Support for innovation and market uptake under Horizon 2020 energy efficiency, Publication of the European Union, Executive Agency for Small and Mediumsized Enterprises (2018).
2. K.B. Janda. Buildings don't use energy: people do. Architectural Science Review, 54:1, pp. 15-22, (2011).

3. E. Shove. Gaps, barriers and conceptual chasms: theories of technology transfer and energy in buildings. Energy Policy, 26, pp. 1105-1112 (1998).

4. K.B. Janda. Building communities and social potential: Between and beyond organizations and individuals in commercial properties. Energy Policy, 67, pp. 48-55 (2014).

5. M. Moezzi, M. Iyer, L. Lutzenhiser, J. Woods. Behavioral Assumptions in Energy Efficiency Potential Studies. Oakland, CA: California Institute for Energy Efficiency (2009).

6. M. Moezzi, K.B. Janda. From "if only" to "social potential" in schemes to reduce building energy use. Energy Research \& Social Science, 1, pp. 30-40 (2014).

7. B.K. Sovacool. Energy studies need social science. Nature, 511, (7511), pp. 529-530 (2014).

8. S. D'Oca, C-F. Chen, T. Hong, Z. Belafi. Synthesizing building physics with social psychology: An interdisciplinary framework for context and occupant behavior in office buildings. Energy Research \& Social Science, 34, pp. 204-251 (2017).

9. A. Cooper. Building a socio-technical energy research community: Theory, practice and impact. Energy Research \& Social Science, 26, pp. 115-120 (2017).

10. R. Galvin. Humans and stuff: Interweaving social and physical science in energy policy research. Energy Research \& Social Science, 26, pp. 98-102 (2017).

11. J. Gluesing. Being There: The Power of Conventional Ethnographic Methods. In Advancing Ethnography in Corporate Environments: Challenges and Emerging Opportunities, ed. Brigitte Jordan. Walnut Creek (CA): Left Coast Press Inc. pp. 23-37 (2013).

12. B. Jordan, B. Dalal. 2006. Persuasive Encounters: Ethnography in the Corporation. Field Methods, 18 (4), pp. 1-24 (2006).

13. K. Mackley, S. Pink. From Emplaced Knowing to Interdisciplinary Knowledge. The Senses and Society, 8:3, pp. 335-353 (2013).

14. M. Cefkin. Ethnography and the Corporate Encounter: Reflections on Research in and of Corporations. New York and Oxford: Berghahn Books (2009).

15. S. Ladner, Sam. Practical Ethnography: A Guide to Doing Ethnography in the Private Sector. Walnut Creek: Left Coast Press (2014).

16. S. Pink, J. Morgan. Short-term Ethnography: Intense Routes to Knowing. Symbolic Interaction, 36(3), pp. 351-361 (2013). 